\title{
Cognitive Functions in Children and Adults with Moyamoya Vasculopathy: A Systematic Review and Meta-Analysis
}

\author{
Annick Kronenburg, ${ }^{\mathrm{a}}$ Esther van den Berg, ${ }^{\mathrm{b}}$ Monique M. van Schooneveld, ${ }^{\mathrm{c}}$ Kees P. J. Braun, ${ }^{\mathrm{a}}$ \\ Lionel Calviere, ${ }^{\mathrm{d}}$ Albert van der Zwan, ${ }^{\mathrm{a}}$ Catharina J. M. Klijn ${ }^{\mathrm{a}, \mathrm{e}}$ \\ aDepartment of Neurology and Neurosurgery, Brain Center Rudolf Magnus, University Medical Center (UMC) Utrecht, Utrecht, The Netherlands \\ ${ }^{b}$ Department of Neurology, Erasmus MC University Medical Center, Rotterdam, the Netherlands \\ 'Sector of Neuropsychology, Department of Pediatric Psychology, Wilhelmina Children's Hospital, UMC Utrecht, Utrecht, The Netherlands

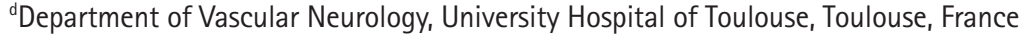 \\ 'Department of Neurology, Donders Institute for Brain, Cognition and Behavior, Center for Neuroscience, Radboud University Medical \\ Center, Nijmegen, the Netherlands
}

Background and Purpose Patients with moyamoya vasculopathy (MMV) may experience cognitive impairment, but its reported frequency, severity, and nature vary. In a systematic review and metaanalysis, we aimed to assess the presence, severity, and nature of cognitive impairments in children and adults with MMV.

Methods We followed the MOOSE guidelines for meta-analysis and systematic reviews of observational studies. We searched Ovid Medline and Embase for studies published between January 1, 1969 and October 4, 2016. Independent reviewers extracted data for mean intelligence quotient (I0) and standardized z-scores for cognitive tests, and determined percentages of children and adults with cognitive deficits, before and after conservative or surgical treatment. We explored associations between summary measures of study characteristics and cognitive impairments by linear regression analysis.

Results We included 17 studies (11 studies reporting on 281 children, six on 153 adults). In children, the median percentage with impaired cognition was 30\% (range, 13\% to 67\%); median I0 was 98 (range, 71 to 107). Median z-score was -0.39 for memory, and -0.43 for processing speed. In adults, the median percentage with impaired cognition was 31\% (range, $0 \%$ to 69\%); median I0 was 95 (range, 94 to 99). Median z-scores of cognitive domains were between -0.9 and -0.4 , with multiple domains being affected. We could not identify determinants of cognitive impairment.

Conclusions A large proportion of children and adults with MMV have cognitive impairment, with modest to large deficits across various cognitive domains. Further studies should investigate determinants of cognitive deficits and deterioration, and the influence of revascularization treatment on cognitive functioning.
Correspondence: Annick Kronenburg Department of Neurology and Neurosurgery, Brain Center Rudolf Magnus, UMC Utrecht, G03.124, PO Box 85500,3508 GA, Utrecht, the Netherlands

Tel: $+31-88-7557059$

Fax: $+31-88-7557059$

E-mail: A.kronenburg@umcutrecht.nl

Received: May 26, 2018

Revised: September 2, 2018

Accepted: September 3, 2018

Keywords Moyamoya disease; Intelligence; Child; Adult; Neuropsychological tests; Review

Copyright (C) 2018 Korean Stroke Society

This is an Open Access article distributed under the terms of the Creative Commons Attribution Non-Commercial License (http://creativecommons.org/licenses/by-nc/4.0/) which permits unrestricted non-commercial use, distribution, and reproduction in any medium, provided the original work is properly cited. 


\section{Introduction}

Moyamoya vasculopathy (MMV) is a cerebrovascular disorder of largely unknown etiology characterized by progressive stenosis or occlusion of the supraclinoid internal carotid arteries and their proximal branches. ${ }^{1,2}$ Patients may present with transient ischemic attacks (TIAs) and ischemic stroke but also with headache, movement disorders, and seizures. ${ }^{1,3}$ MMV can also lead to cognitive impairment. ${ }^{4}$ Cognitive functions may not only be affected by overt or silent brain infarcts or hemorrhages but also by chronic hypoperfusion, as cognitive impairment has been diagnosed in adults with MMV without stroke. ${ }^{5}$ Early age of onset and longer disease duration have been associated with the occurrence of cognitive impairment. ${ }^{6}$ Many patients with MMV undergo surgical revascularization to improve cerebral blood flow (CBF) and prevent future ischemic stroke, ${ }_{1}^{2}$ but prospective studies on the effect of surgical treatment on cognition are lacking. A previously published descriptive review has provided an overview on cognition in moyamoya disease (MMD) suggesting that the impact of MMV on cognition is more pronounced in children than in adults. ${ }^{7}$ In the present study we systematically collected and meta-analyzed available quantitative information on the presence, severity and nature of cognitive impairment in children and adults with MMV and its determinants, in particular cerebral perfusion. Furthermore, we aimed to determine the effect of surgical intervention on cognition.

\section{Methods}

For the conduction of this systematic review we followed the meta-analysis of observational studies in epidemiology (MOOSE) guidelines. ${ }^{8}$

\section{Search strategy and selection criteria}

We searched Ovid Medline and Embase for publications of studies describing cognitive function in patients with MMV published between January 1, 1969 (the year the disorder was given its name) and October 4, 2016 (see online Supplementary for Syntax). No limits were set for languages; native speakers translated papers that were written in other languages than English, German, or French. Titles and abstracts were scanned and papers were included on the basis of full text by two authors independently (A.K. and C.J.M.K.); disagreement was resolved by consensus. Additional studies were included from the reference lists of included studies. We included studies reporting cognitive or intellectual functioning in children and adults that allowed analysis of quantitative data on group level (i.e., intelligence quotient [I0] scores) of at least five patients. If au- thors reported neuropsychological assessment without providing raw neuropsychological data, we contacted them for additional data. In case of (suspected) overlap between study cohorts, we included the study with the largest sample size with information on the proportion of patients with impaired cognition. In case individual patient data were provided, we excluded patients without quantitative cognitive data.

\section{Data extraction}

Three authors (A.K. all papers; C.J.M.K. and E.B. half of the studies each) independently extracted data from selected papers. Disagreements were solved by consensus. Of the authors from 13 publications who were approached for additional data, one provided baseline characteristics and scores of neuropsychological tests, ${ }^{9}$ five could not provide additional information, and seven authors did not respond. The risk of bias was evaluated by one author (A.K.) using the Newcastle-Ottawa scale adapted for cross-sectional studies (see online Supplementary for the Risk Assessment). ${ }^{10}$

We collected the following study characteristics: study design; midyear of study; in- and exclusion criteria; number of patients with MMD or moyamoya syndrome (MMS, known associated disease) ${ }_{i}^{1}$ mean age and duration of symptoms (at time of diagnosis; presentation; neuropsychological assessment, operation, inclusion or not specified); proportion of females; ethnicity (Asian, Caucasian, Hispanic, African, and AfroAmerican, according to the definition provided by the authors, or-if not provided-by country of publication); site of clinical stroke or TIA (uni- or bilateral); application of diagnostic criteria for $\mathrm{MMV}^{1}{ }^{1}$ site of vasculopathy; and site of (silent) stroke on imaging; and results of CBF and cerebrovascular reserve (CVR) studies. We divided presenting symptoms into four categories depending on the information provided by the authors: (1) ischemic stroke only; (2) TIA(s) only; (3) hemorrhage; or (4) other symptoms. We collected information on the level of education and occupation. In studies that provided longitudinal assessment of cognitive functioning, data were also collected for the second time-point, including the type of revascularization in surgically treated patients.

From the neuropsychological assessments we extracted the following data: mean full-scale intelligent quotient (FSIO), developmental quotient (DQ) (pooled with FSIO as IQ); verbal intelligent quotient (VIQ); performance intelligent quotient (PIQ); raw or standardized z-scores of cognitive tests; and the proportion of patients with cognitive impairment overall and per cognitive domain (Supplementary Table 1 summarizes the specific neuropsychological tests applied by each study). For studies that did not provide the proportion of patients with cognitive impairment, we 
calculated the proportion based on published normative data if possible. For DQ (a ratio calculated by dividing the mental developmental age with the chronological age) we appointed to have the same norm sample as (FS)IQ, unless otherwise specified." Cognitive test results derived from neuropsychological evaluation were grouped into six predefined cognitive domains according to standard neuropsychological practice specified in Lezak: intelligence, memory, processing speed, attention and executive functions, visual perception and construction, and language (Supplementary Table 2). ${ }^{12}$ In studies that provided results of multiple cognitive tests investigating the same domain, we determined the mean score and, if possible, calculated the mean zscores and standard deviations (SDs) for the domain. A z-score is a standardized score which entails the number of SDs that an individual test result differs from the mean score in healthy controls, thereby indicating the relative location of a measurement within its distribution. ${ }^{13}$

\section{Data analysis}

To assess the presence of cognitive impairment, we determined the median proportion of patients with cognitive impairment. Cognitive impairment was defined according to the authors' criteria, or as a cognitive score (overall, or on a specific domain, or on at least two tests) deviating more than 1.5 SD from the population mean, or $10<85$. To assess the severity of the impairment, we calculated the median cognitive scores of the various cognitive tests. To determine whether mean age, ethnicity, sex, mean duration of symptoms, and presenting symptoms were determinants of cognitive impairment, we performed linear regression analysis weighted by the inverse standard error of the proportion of patients with impaired cognition. Due to lack of data, this could not be performed for other patients' characteristics. We qualitatively determined the reported association between frontal CBF and CVR and cognitive impairment as reported by the authors.

In studies that provided longitudinal assessment of cognitive function, we determined whether cognitive functions improved, deteriorated or remained stable over time. For intelligence, we used a cut-off point of more than 10 points differences of IQ scores at follow-up. For cognitive domains, change over time was categorized according to the criteria provided by the authors.

\section{Results}

After screening 299 studies (66 studies were screened on full text), we included 17 studies reporting cognitive function in a total of 434 patients (Figure 1). Eleven studies reported on 281 children and six studies on 153 adults. Tables 1 and 2 and Supplementary Tables 3 and 4 summarize study and disease characteristics and neuropsychological test results. ${ }^{4,6,9,14-27}$ Four studies reported on cerebral hemodynamic measures in relation to cognitive functions. ${ }^{4,9,17,21}$ Nine studies reported longitudinal assessment of cognitive function over time, eight of which provided data after surgical treatment in children; one after conservative treatment in adults (Table 2 and Supplementary Table 5), ${ }^{4,15-20,22,23}$ Study quality varied between three and six out of seven: three studies had a total score of $3 ; ;^{4,21,22}$ five studies a score of $4 i^{16,18-20,23}$ five studies a score of $5 ;, 6,9,17,25,27$ and four studies a score of 6. 14,15,24,26 The most important reasons for studies having a risk of bias were: sample size $<30$ patients (65\%) and no information on whether patients were included consecutively (87\%) (Supplementary Table 6).

\section{Children}

In the 11 studies reporting on children, median age of the study cohorts was 9.4 years (range, 5.9 to 13.9); the median percentage females 55\% (range, 33\% to 75\%; 10 studies, 268 patients). All studies except one ${ }^{14}$ described Asian cohorts of which nine were Japanese. Two studies described the criteria they used for the diagnosis of MMV: confirmation by angio-

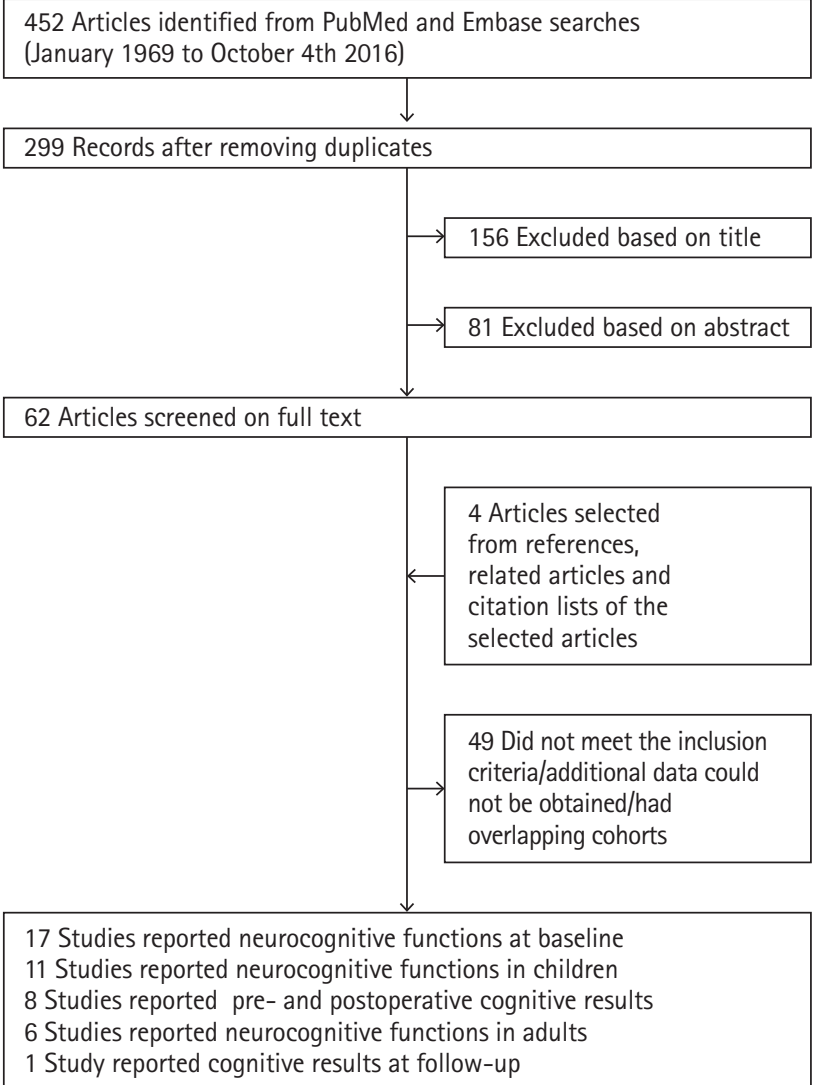

Figure 1. Flowchart. 


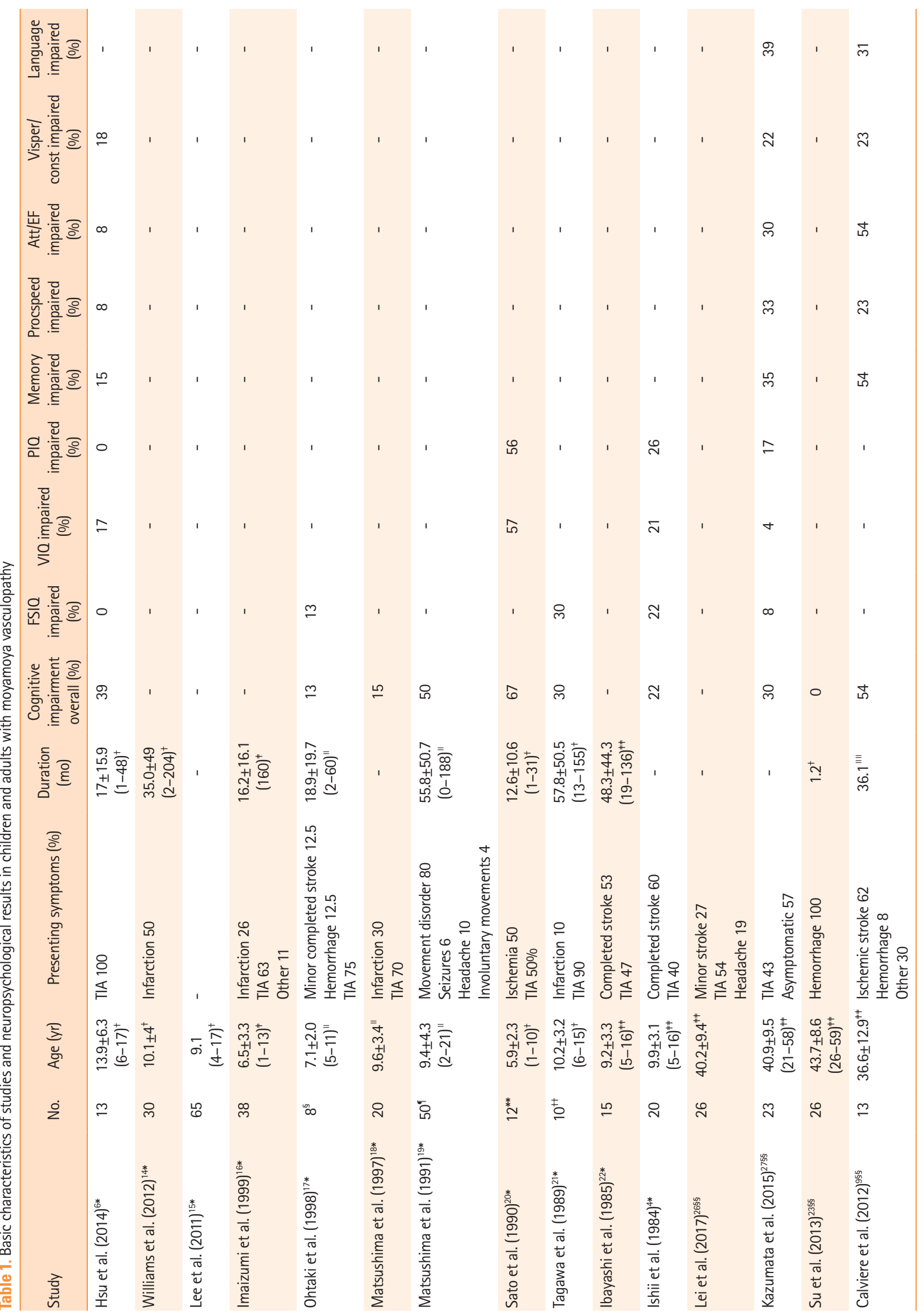




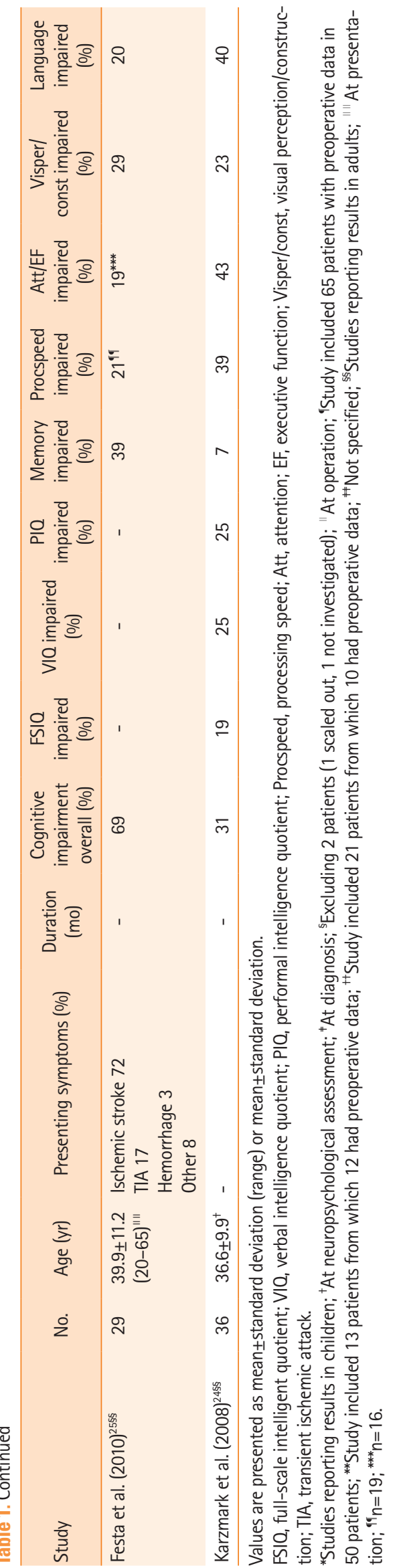

graphic evidence of moyamoya collaterals and stenosis in one study ${ }^{14}$ and according to Sato et al. $^{20}$ in the other. One paper reported the inclusion of patients with MMS $(n=20) .{ }^{14}$ Presenting symptoms were reported in 10 studies (216 children). The median proportion of children presenting with ischemic stroke was 31\% (range, 0\% to 60\%; nine studies, 166 patients), and with TIA only 69\% (range, 40\% to 100\%; nine studies, 166 patients). ${ }^{4,614,16-18,20-22}$ Presentation with hemorrhage was rare (one patient in 166 children in nine studies). One study (50 patients) did not report symptoms that could be classified according to our predefined categories. ${ }^{19}$

The median duration of symptoms was 27.0 months (range, 12.6 to 57.8). We found no information on school performance or the presence of depression among the pediatric studies.

\section{Cognitive impairment}

The median proportion of children with cognitive impairment overall was 30\% (range, 13\% to 67\%; seven studies, 133 patients) (Figure 2) with a median IQ score of 101 (range, 71 to 107). ${ }^{4,6,17-21}$ In the included 11 studies, the median I0 score was 98 (range, 71 to 107), ${ }^{4,6,14-22}$ median VIO score was 97 (range, 77 to 108; seven studies, 170 children), 4,6,14,15,18,20,22 and median PIO score was 100 (range, 89 to 109; six studies, 163 children). ${ }^{4,6,14,15,18,22}$ Three studies reported on specific cognitive domains. ${ }^{6,14,15}$ Memory was affected in 15\% of patients (one study, 13 patients). ${ }^{6}$ Eight percent of the patients had impairment in processing speed and attention and executive functions, and $18 \%$ in the visual perception and construction domain (one study, 13 patients). ${ }^{6}$ The median z-score for memory was -0.39 (range, -0.85 to 0.45 ; three studies, 108 children) ${ }^{6,14,15}$ and for processing speed -0.43 (range, -0.86 to 0.00 ; two studies, 43 children). ${ }^{6,14}$ One study (13 patients) assessed additional domains with mean z-scores of 0.50 for attention and executive function; and -0.53 for visual perception and construction. ${ }^{6}$

We found no association between mean age $(B=-0.014$; 95\% confidence interval $[\mathrm{Cl}],-0.112$ to $0.083 ; P=0.723)$; type of presenting symptom (for infarction $[B=-0.002 ; 95 \% \mathrm{Cl}$, -0.017 to $0.013 ; P=0.672]$ and for TIA $[B=-0.002 ; 95 \% \mathrm{Cl}$, -0.013 to $0.017 ; P=0.672)$; mean duration of symptoms $(\mathrm{B}=0.000 ; 95 \% \mathrm{Cl},-0.016$ to $0.016 ; P=0.945)$; and proportion of females $\left(B=-0.005 ; 95 \% C l_{1}-0.025\right.$ to $\left.0.014 ; P=0.508\right)$, and the proportion of patients with cognitive impairment (Supplementary Table 7). 4,6,18,20,21

\section{Cerebral blood flow}

Three studies investigated the relation between CBF (xenon-enhanced computed tomography $[\mathrm{CT}]^{4}$ or single photon emission CT [SPECT] $)^{17}$ and IQ scores. ${ }^{21}$ In one study, patients with a lower 
Table 2. Longitudinal neuropsychological test performances

\begin{tabular}{|c|c|c|c|c|c|}
\hline Study & FU period (mo) & $\begin{array}{l}\text { Impairment overall (A/B) } \\
(\%)^{*}\end{array}$ & Improved (\%) & Stable $(\%)$ & Deteriorated $(\%)$ \\
\hline Lee et al. (2011) & $\begin{array}{c}19^{\ddagger} \\
(5-46)\end{array}$ & - & - & - & - \\
\hline Imaizumi et al. (1999) ${ }^{16 t}$ & $>120^{\S}$ & - & - & - & - \\
\hline Ohtaki et al. (1998) $)^{17+}$ & $\begin{array}{c}85.2 \pm 32.59^{\prime \prime} \\
(23-110)\end{array}$ & $13 / 13$ & 12 & 63 & 25 \\
\hline Matsushima et al. (1997) & $113^{*}$ & $15 / 20$ & - & - & - \\
\hline Matsushima et al. (1991) & $\begin{array}{c}26.2 \pm 14.7^{\ddagger} \\
(7-58)\end{array}$ & $50 / 49$ & 27 & 49 & 24 \\
\hline Sato et al. $(1990)^{20+}$ & $\begin{array}{c}44.4 \pm 26.3^{\prime} \\
(4-99)\end{array}$ & $67 / 58$ & $\begin{array}{c}\text { PIO } 11 \\
\text { VIO } 29 \\
\text { DO } 0\end{array}$ & $\begin{array}{l}\text { PIO } 78 \\
\text { VIO } 57 \\
\text { DO } 100\end{array}$ & $\begin{array}{c}\text { PIO } 11 \\
\text { VIO } 14 \\
\text { DQ } 0\end{array}$ \\
\hline Ibayashi et al. (1985) $22+$ & $\begin{array}{c}6.5 \pm 4.9^{\ddagger} \\
(1-17)\end{array}$ & - & $\begin{array}{l}\text { FSIO } 47 \\
\text { VIO } 20 \\
\text { PIO } 60\end{array}$ & - & - \\
\hline Ishii et al. $(1984)^{4+}$ & $6-68^{+}$ & $22 /-$ & $\begin{array}{l}\text { FSIO } 53 \\
\text { VIO } 13 \\
\text { PIO } 67\end{array}$ & $\begin{array}{l}\text { FSIQ } 40 \\
\text { VIO } 73 \\
\text { PIO } 20\end{array}$ & $\begin{array}{l}\text { FSIO } 6 \\
\text { VIO } 13 \\
\text { PIO } 13\end{array}$ \\
\hline Su et al. $(2013)^{23 * *}$ & $24^{\prime \prime}$ & $0 / 100$ & 0 & 0 & 100 \\
\hline
\end{tabular}

Values are presented as median (range), mean \pm standard deviation (range), or range.

FU, follow-up; PIQ, performal intelligence quotient; VIQ, verbal intelligence quotient; DQ, developmental quotient; FSIQ, full-scale intelligent quotient.

${ }^{*} \mathrm{~A} / \mathrm{B}$, prior neuropsychological test result/longitudinal neuropsychological test result; ${ }^{+}$Studies reporting results in children; ${ }^{*} \mathrm{FU}$ period defined as time of operation to NPA; ${ }^{~} \mathrm{FU}$ period defined as time from onset of disease to neurospychological assessment; " FU period defined as time of NPA to NPA; 'FU period unspecified; **Studies reporting results in adults.

IO showed a tendency for a more marked depression of mean $\mathrm{CBF}$ than those with a normal IQ (quantitative analysis not provided). ${ }^{4}$ Another study reported a marked depression of $\mathrm{CBF}$ (qualitatively determined) in the frontal lobes in seven out of nine patients, all having normal 10 scores. ${ }^{17}$ The third study reported no relation between abnormal patterns of $\mathrm{CBF}$ and $\mathrm{IQ} .^{21}$

\section{Longitudinal results}

Eight studies (199 patients) evaluated the effect of revascularization surgery on cognitive performances after a median follow-up period of 35.3 months (range, 6.5 to 113 ).,15-20,22 All eight studies reported $I 0$ and one also assessed memory. Indirect revascularization was performed in $90.5 \%$ of the patients, direct in $0.5 \%$ and combined in $9 \%$. The median proportion of children with impaired intelligence pre-operatively was 33\% (range, 13\% to 67\%; four studies, 88 children) and at followup after revascularization 35\% (range, 13\% to 58\%; four studies, 81 children). ${ }^{17-20}$ In the other four studies proportions of children with impaired IOs were not reported post-operatively.

Median scores at follow-up were: for 1097 (range, 68 to 108; six studies, 161 children) with a pre-operative median 10 score in these studies of 101 (range, 71 to 107; 170 children); for VIO 97 (range, 82 to 106; four studies, 107 children) with a pre-operative median VIO score of 101 (range, 77 to 108; 107 children); and for PIO 102 (range, 100 to 109; three studies, 100 children) with a pre-operative median PIO score of 100 (range, 97 to 109; 100 children).

Based on available individual patient data, improvement in 10 ( $\geq 10$ points) was observed in a median proportion of $27 \%$ of patients (range, 5.5\% to 53\%; five studies, 91 children), $4,17,19,20,22$ no change in 56\% (range, 40\% to 89\%; four studies, 76 children) and deterioration in 15\% (range, 5.5\% to 25\%; four studies, 76 children). Improvement in VIO was seen in 20\% (range, 13\% to 29\%; three studies, 37 children), ${ }^{40,22}$ no change in 65\% (57\% and 73\%; two studies, 22 children) and deterioration in 13.5\% (13\% and 14\%; two studies, 22 children). PIO scores improved in $63.5 \%$ (60\% and 67\%; two studies, 30 patients), remained stable in 20\% (one study, 15 patients) and deteriorated in 13\% (one study, 15 patients). ${ }^{4,22}$ Memory function improved after surgery (pre-operative z-score 0.45 ; after surgery 0.77 ). ${ }^{15}$ One study in which 18 out of the 38 patients were operated on (five combined, 13 indirect) reported no improvement of IQ after revascularization (no quantitative data available). ${ }^{16}$

\section{Adults}

In the six studies reporting on adults, median age was 40.1 years (range, 36.6 to 43.7 ) and the median percentage of females $63 \%$ (range, $46 \%$ to $74 \%$ )., ${ }^{9,23-27}$ Of a total of 153 pa- 
tients, 87 were Asian (57\%), 56 Caucasian (37\%), and 10 had another ethnicity (7\%). The median proportion of adults presenting with ischemic stroke was $27 \%$ (range, $0 \%$ to $72 \%$; five studies, 117 patients), TIA only 17\% (range, 0\% to 54\%; five studies, 117 patients), hemorrhage 3\% (range, 0\% to 100\%; five studies, 117 patients), and 19\% (range, 0\% to 57\%; five studies, 117 patients) had other symptoms. ${ }^{9,23,25-27}$ The median duration of symptoms at assessment or inclusion was 18.6 months (1.2 and 36.1 months; two studies).

\section{Cognitive impairment}

The median proportion of patients with cognitive impairment was 31\% (range, 0\% to 69\%; five studies, 127 patients). ${ }^{9,23-25,27}$ In the four studies investigating cognition by means of a neuropsychological test battery, the median proportion with impaired cognition on one or more of the reported domains was $42.5 \%$ (range, 30\% to 69\%). 9,24,25,27 The median I0 score was 95 (range, 94 to 99; three studies, 88 patients); ${ }_{1}^{24,25,27}$ median VIO score was 94 and median PIQ score 93 (two studies, 59 patients).

Four studies (101 patients) reported on specific cognitive domains. ${ }^{9,24,25,27}$ The median proportion of patients with impaired memory was $37 \%$ (range, $7 \%$ to 54\%), impaired processing speed $28 \%$ (range, $21 \%$ to $39 \%$ ), impaired attention and execu- tive functions 37\% (range, 19\% to 54\%), impaired visual perception and construction 23\% (range, 22\% to 29\%), and impaired language 35\% (range, 20\% to 40\%)., 94,25,27 The median z-scores (three studies, 78 patients) were: for memory -0.4 (range, -1.1 to -0.2 ), for processing speed -0.9 (range, -1.7 to -0.8 ), for attention and executive function -0.9 (range, -0.95 to -0.4 ), for visual perception and construction -0.4 (range, -0.5 to -0.2 ), and for language -0.6 (range, -0.8 to -0.15 ). One study of patients with an intraventricular hemorrhage (IVH) showed a mean score within the normal range (27.4 \pm 1.2 [range, 26 to 29]) on the Montreal Cognitive Assessment (MoCA). ${ }^{23}$

We found no association between mean age $(B=-0.044$; $95 \% \mathrm{Cl}_{1}-0.184$ to $\left.0.096 ; P=0.387\right)$ or proportion of females ( $\mathrm{B}=0.011 ; 95 \% \mathrm{Cl},-0.031$ to $0.053 ; P=0.460)$ and cognitive impairment (Supplementary Table 7). Analysis of the association of type of presenting symptom and cognitive impairment was not possible, because of lack of data categorized according to our predefined classification.

The mean duration of education was $12.1 \pm 3.1$ years (three studies, 91 patients). ${ }^{24-26}$ In a series of 26 patients from one study, nine finished college or a higher-level education, five primary school or less, and 12 middle school. ${ }^{23}$ Another study of 36 patients reported that 25 participated in a full-time job,

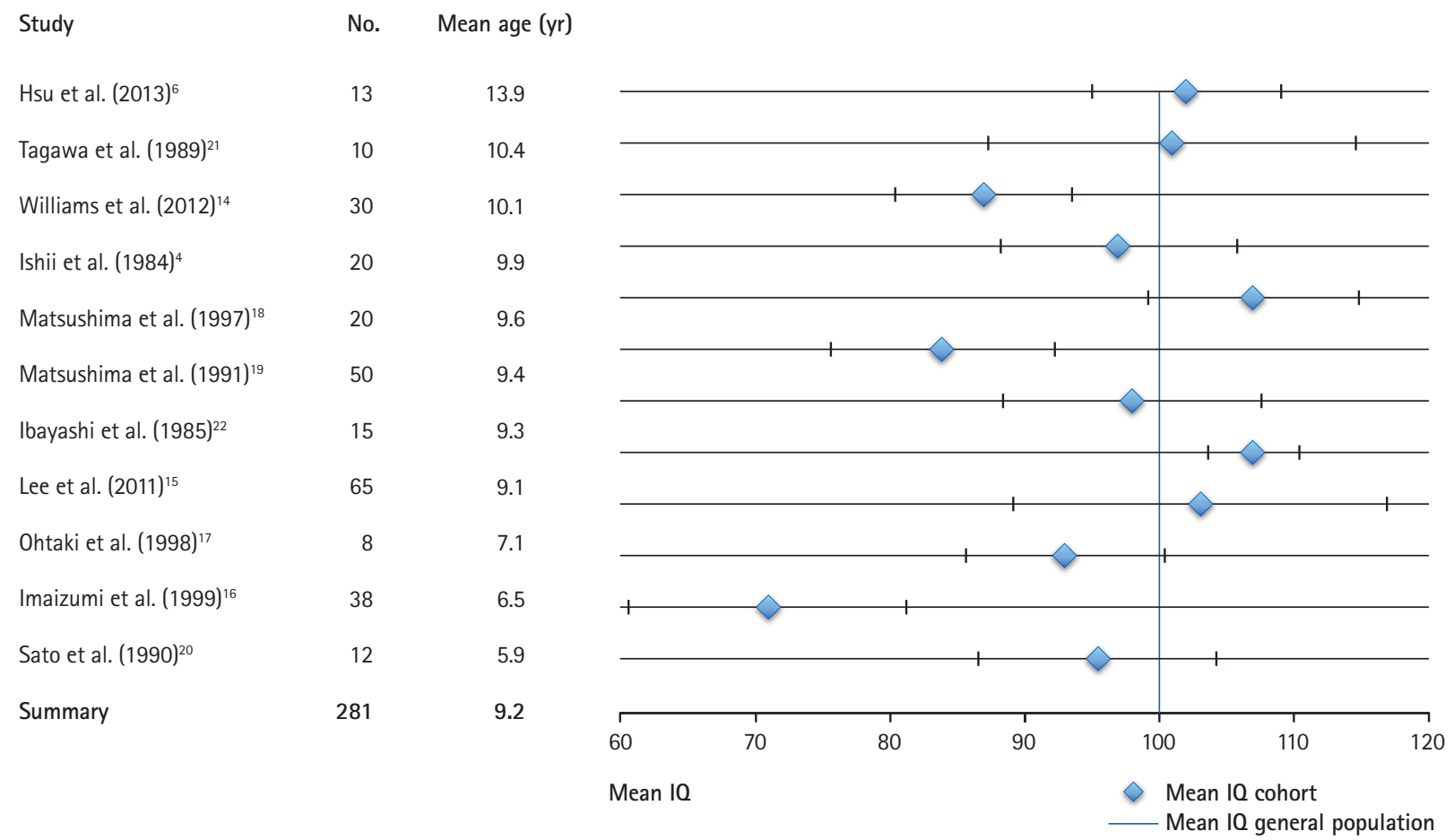

Figure 2. Mean intelligence quotient (IO) with 95\% confidence interval $(\mathrm{Cl})$ in children (11 studies, 281 children) ordered by mean age (mean summary 10 , $95.5 ; 95 \% \mathrm{Cl}, 86.7$ to 104.2 ). The blue vertical line represents the mean $\mathrm{IQ}$ in the average population. 
five were unemployed and five were homemakers; one patient had retired. ${ }^{24}$

\section{Cerebral blood flow studies}

One study reported a correlation of the apparent diffusion coefficient (ADC) in normal appearing frontal white matter on diffusion weighted imaging with CVR on perfusion magnetic resonance imaging and executive functions (Spearman coefficient, $-0.46 ; P=0.01) .^{9}$ Elevation of $A D C$ was significantly correlated with executive dysfunction (area under the curve for cognitive impairment, $0.85 ; 95 \% \mathrm{Cl}, 0.59$ to $1.16 ; P=0.032$ ).

\section{Longitudinal results}

In the study assessing cognitive impairment in patients with solely IVH, all patients had normal MoCA scores at baseline (mean MoCA score 27.4 \pm 1.2 [range, 26 to 39]) and mild cognitive impairments after a mean follow-up of 24 months (mean MoCA score $18.7 \pm 1.3$ [range, 16 to 21]) without treatment. ${ }^{23}$

\section{Discussion}

Our systematic review shows that around 30\% of children and of adults have cognitive impairment. When assessed on a group level, median 10 scores are within the normal range in both children and adults. Information on specific domains of cognitive function is limited, with relatively modest impairments in memory and processing speed observed in children, and modest to large impairments across various cognitive domains in adults.

Since there was not a large discrepancy between VIO and PIO, total IO scores provide a reliable insight in cognitive functioning in children. Longitudinal results in children showed that 10 scores on a group level remained within normal limits over time. In adults, longitudinal studies of neuropsychological assessments other than with a screening test have not been performed.

In a previous review, the authors concluded that cognition is affected more frequently in children than in adults, reporting intelligence to be impaired in children, and executive functions in adults. ${ }^{7}$ However, our systematic review and meta-analysis show that in adults the proportion of patients with impairment of cognitive function is as large as in children. In comparison with this aforementioned review, we included five additional studies on children ${ }^{6,14,15,21,22}$ and four recent studies on adults; $9,23,26,27$ and excluded studies without quantitative data. Although the highest median percentage of impaired function was found in the domain attention and executive functions, we found similar proportions of patients with impairment for the other cognitive domains. In children, other domains than intelligence were investi- gated in only three studies. Patients with a normal intelligence may show selective cognitive impairment in other cognitive domains. Therefore, extensive neuropsychological evaluation is of great importance, also in children who generally show a diffusely impaired cognitive profile in case of cognitive deterioration because their brain is still developing.

It remains uncertain if the neurocognitive profile of patients with MMS differs from that in patients with MMD, since the presence of associated diseases was reported in only one study, which did not demonstrate a difference between these groups. ${ }^{14}$

We did not find an association between the predefined determinants and the proportion of patients with cognitive impairment, probably due to the limited data available. Some of the included studies suggested that age at onset ${ }^{4,6,22}$ and longer duration of disease were ${ }^{6}$ associated with cognitive dysfunction, however we could not confirm these associations in our metaanalysis. Previous studies were small including 13 to 20 patients and observed associations may have been due to chance. Information on the determinants of cognitive impairment and its course is scarce. The relation between cerebral perfusion and cognition in children remains unclear, whereas in adults, a single study suggested a relation between diminished perfusion in the frontal matter and executive dysfunction. Several studies have suggested that (frontal) hypoperfusion, white matter disease and infarction are associated with cognitive disturbances. ${ }^{28-31}$ It remains unclear whether MMV directly affects cognition by chronic hypoperfusion, or that cognitive impairment is mainly the result of stroke. The observed impaired cognition in patients without stroke supports the hypothesis that chronic hypoperfusion is a contributing factor to cognitive impairment in patients with MMV., ${ }^{5,6}$ One study reported that executive dysfunction was associated with stroke and white matter lesions and not with CVR; however, patients with higher baseline CBF had better cognitive functioning. ${ }^{32}$ Improvement in intelligence and cerebral perfusion in children has been observed after revascularization surgery, $y^{4,17}$ and for this reason frontal revascularization procedures are performed more often..$^{2,17,33}$ Whether prevention of cognitive decline should be an indication for revascularization surgery in patients with MMV remains unclear. Although our review shows that a fair number of patients improved or remained stable after revascularization, the quantity of the included data is too limited to draw final conclusions.

Although we were able to collect a reasonable amount of data on cognitive function in patients with MMV, the review was limited by the relatively low number of patients described in the individual studies. Information bias could not be avoided, given the large heterogeneity of the reported cognitive tests. Since little information on patients' characteristics was avail- 
able, results could be influenced by selection bias and we could not control for confounding factors like the presence of silent infarction on imaging. Finally, we were not able to perform meta-analysis of the relation between CBF and cognition and of the effect of revascularization due to the low number and heterogeneity of studies. Our review also has strengths. We were able to quantify cognitive impairments in MMV. In addition, we were able to eliminate the risk of selection bias due to language since we did not include language restrictions. Despite these methodological shortcomings, our results give valuable insight in the presence, severity and nature of cognitive functions in MMV before and after revascularization, since we quantified cognitive impairments in MMV.

\section{Conclusions}

Large prospective studies with a standardized neuropsychological test battery are needed to determine the severity of cognitive impairment and the domains affected. Information on school level and performance, and on work status is also of importance, since it reflects function rather than deficits. ${ }^{34}$ It remains to be established whether cognitive outcome can be improved by revascularization surgery.

\section{Supplementary materials}

Supplementary materials related to this article can be found online at https://doi.org/10.5853/jos.2018.01550.

\section{Disclosure}

The authors have no financial conflicts of interest.

\section{Acknowledgments}

We thank Dr. M. Poon (Buckinghamshire, England), S. Diederen and R. Hendriks (Utrecht, the Netherlands) for supporting the translation of the Chinese and Japanese papers.

This work was supported by the Dutch Brain Foundation (2012(1)-179); the Christine Bader Fund Irene Children's Hospital); the Tutein Nolthenius Oldenhof Fund, the Johanna Children Fund and Friends of the Wilhelmina Children's Hospital.

Dr. Catharina J. M. Klijn is supported by a Clinical Established Investigator grant from the Dutch Heart Foundation (grant number 2012T077) and an Aspasia grant from ZonMw (grant number 015008048).

\section{References}

1. Scott RM, Smith ER. Moyamoya disease and moyamoya syndrome. N Eng/ J Med 2009;360:1226-1237.

2. Kronenburg $A$, Braun $K P$, van der Zwan $A$, Klijn CJ. Recent advances in moyamoya disease: pathophysiology and treatment. Curr Neurol Neurosci Rep 2014;14:423.

3. Kleinloog R, Regli L, Rinkel GJ, Klijn CJ. Regional differences in incidence and patient characteristics of moyamoya disease: a systematic review. J Neurol Neurosurg Psychiatry 2012;83:531-536.

4. Ishii $R$, Takeuchi S, Ibayashi K, Tanaka R. Intelligence in children with moyamoya disease: evaluation after surgical treatments with special reference to changes in cerebral blood flow. Stroke 1984;15:873-877.

5. Karzmark P, Zeifert PD, Bell-Stephens TE, Steinberg GK, Dorfman $\sqcup$. Neurocognitive impairment in adults with moyamoya disease without stroke. Neurosurgery 2012;70:634-638.

6. Hsu YH, Kuo MF, Hua MS, Yang CC. Selective neuropsychological impairments and related clinical factors in children with moyamoya disease of the transient ischemic attack type. Childs Nerv Syst 2014;30:441-447.

7. Weinberg DG, Rahme RJ, Aoun SG, Batjer HH, Bendok BR. Moyamoya disease: functional and neurocognitive outcomes in the pediatric and adult populations. Neurosurg Focus 2011;30:E21.

8. Stroup DF, Berlin JA, Morton SC, Olkin I, Williamson GD, Rennie $D$, et al. Meta-analysis of observational studies in epidemiology: a proposal for reporting. Meta-analysis Of Observational Studies in Epidemiology (MOOSE) group. JAMA 2000;283:2008-2012.

9. Calviere L, Ssi Yan Kai G, Catalaa I, Marlats F, Bonneville F, Larrue $V$. Executive dysfunction in adults with moyamoya disease is associated with increased diffusion in frontal white matter. $J$ Neurol Neurosurg Psychiatry 2012;83:591-593.

10. Herzog R, Álvarez-Pasquin MJ, Díaz C, Del Barrio JL, Estrada $J M, G i l$ Á. Are healthcare workers' intentions to vaccinate related to their knowledge, beliefs and attitudes? A systematic review. BMC Public Health 2013;13:154.

11. Kurita $H_{1}$ Osada $H$, Shimizu $K$, Tachimori H. Validity of DQ as an estimate of $\mathrm{IQ}$ in children with autistic disorder. Psychiatry Clin Neurosci 2003;57:231-233.

12. Lezak M, Howieson D, Bigler E, Tranel D. Neuropsychological Assessment. 5th ed. New York, NY: Oxford University Press, 2012.

13. Bowerman BL, O'Connell RT, Hand ML. Business Statistics in Practice. 2nd ed. New York, NY: McGraw Hill Higher Education, 2001.

14. Williams $T S$, Westmacott $R$, Dlamini $N$, Granite $L$, Dirks $P$, 
Askalan $\mathrm{R}$, et al. Intellectual ability and executive function in pediatric moyamoya vasculopathy. Dev Med Child Neurol 2012;54:30-37.

15. Lee JY, Phi JH, Wang KC, Cho BK, Shin MS, Kim SK. Neurocognitive profiles of children with moyamoya disease before and after surgical intervention. Cerebrovasc Dis 2011;31:230-237.

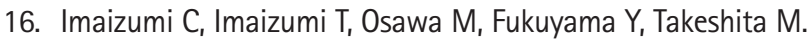
Serial intelligence test scores in pediatric moyamoya disease. Neuropediatrics 1999;30:294-299.

17. Ohtaki M, Uede T, Morimoto S, Nonaka T, Tanabe S, Hashi K. Intellectual functions and regional cerebral haemodynamics after extensive omental transplantation spread over both frontal lobes in childhood moyamoya disease. Acta Neurochir (Wien) 1998;140:1043-1053.

18. Matsushima $Y$, Aoyagi M, Nariai T, Takada $Y$, Hirakawa $K$. Long-term intelligence outcome of post-encephalo-duro-arterio-synangiosis childhood moyamoya patients. Clin Neurol Neurosurg 1997;99 Suppl 2:S147-S150.

19. Matsushima Y, Aoyagi M, Koumo Y, Takasato Y, Yamaguchi T,

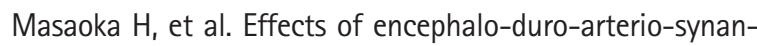
giosis on childhood moyamoya patients: swift disappearance of ischemic attacks and maintenance of mental capacity. Neurol Med Chir (Tokyo) 1991;31:708-714.

20. Sato H, Sato N, Tamaki N, Matsumoto S. Chronic low-perfusion state in children with moyamoya disease following revascularization. Childs Nerv Syst 1990;6:166-171.

21. Tagawa T, Itagaki Y, Mimaki T, Tanaka J, Ito N, Suzuki Y, et al. Intelligence and regional cerebral blood flow in children with Moyamoya disease. No To Hattatsu 1989;21:9-13.

22. Ibayashi $K$, Takeuchi S, Ishii $R$, Tanaka R, Tsuruoka H. Intelligence and memory function of juvenile patients with moyamoya disease. With reference to the effect of surgical treatment. Nerv Syst Child 1985;10:155-161.

23. Su SH, Hai J, Zhang L, Yu F, Wu YF. Assessment of cognitive function in adult patients with hemorrhagic moyamoya disease who received no surgical revascularization. Eur J Neurol 2013;20:1081-1087.

24. Karzmark P, Zeifert PD, Tan S, Dorfman $\sqcup$, Bell-Stephens TE, Steinberg GK. Effect of moyamoya disease on neuropsychological functioning in adults. Neurosurgery 2008;62:1048-1051.
25. Festa JR, Schwarz LR, Pliskin N, Cullum CM, Lacritz L, Charbel $\mathrm{F}$, et al. Neurocognitive dysfunction in adult moyamoya disease. J Neurol 2010;257:806-815.

26. Lei $Y$, Su J, Jiang $H$, Guo $Q$, Ni W, Yang $H$, et al. Aberrant regional homogeneity of resting-state executive control, default mode, and salience networks in adult patients with moyamoya disease. Brain Imaging Behav 2017;11:176-184.

27. Kazumata K, Tha KK, Narita H, Kusumi I, Shichinohe H, Ito M, et al. Chronic ischemia alters brain microstructural integrity and cognitive performance in adult moyamoya disease. Stroke 2015;46:354-360.

28. Karasawa J, Touho H, Ohnishi H, Miyamoto S, Kikuchi $H$. Long-term follow-up study after extracranial-intracranial bypass surgery for anterior circulation ischemia in childhood moyamoya disease. J Neurosurg 1992;77:84-89.

29. Kuroda S, Houkin K, Ishikawa T, Nakayama N, Ikeda J, Ishii N, et al. Determinants of intellectual outcome after surgical revascularization in pediatric moyamoya disease: a multivariate analysis. Childs Nerv Syst 2004;20:302-308.

30. Calviere L, Catalaa I, Marlats F, Viguier A, Bonneville F, Cog-

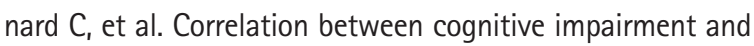
cerebral hemodynamic disturbances on perfusion magnetic resonance imaging in European adults with moyamoya disease. Clinical article. J Neurosurg 2010;113:753-759.

31. Hosoda C, Nariai T, Ishiwata $K$, Ishii K, Matsushima Y, Ohno K. Correlation between focal brain metabolism and higher brain function in patients with moyamoya disease. Int J Stroke 2010;5:367-373.

32. Mogensen MA, Karzmark P, Zeifert PD, Rosenberg J, Marks $\mathrm{M}$, Steinberg GK, et al. Neuroradiologic correlates of cognitive impairment in adult moyamoya disease. AJNR Am J Neuroradiol 2012;33:721-725.

33. Kronenburg A, Esposito G, Fierstra J, Braun KP, Regli L. Combined bypass technique for contemporary revascularization of unilateral MCA and bilateral frontal territories in moyamoya vasculopathy. Acta Neurochir Supp/ 2014;119:65-70.

34. Bulder MM, Hellmann PM, van Nieuwenhuizen 0, Kappelle $\sqcup$, Klijn CJ, Braun KP. Measuring outcome after arterial ischemic stroke in childhood with two different instruments. Cerebrovasc Dis 2011;32:463-470. 
Supplementary for Syntax

\section{OVID Medline (PubMed) syntax}

(moyamoya OR moya OR moya-moya [Title/Abstract]) AND (cognition OR neurocognitive OR intelligence OR psycho OR executive OR cognitive OR mental OR retardation OR memory OR language OR dementia [Title/Abstract])

\section{Embase syntax}

(moyamoya:ab,ti OR moya:ab,ti OR moya moya:ab,ti) AND (cognition:ab,ti OR neurocognitive:ab,ti OR intelligence:ab,ti OR psycho:ab,ti OR executive:ab,ti OR cognitive:ab,ti OR mental:ab,ti OR retardation:ab,ti OR memory:ab,ti OR language:ab,ti OR dementia:ab,ti) 
Supplementary for the Risk Assessment

\section{Newcastle-Ottawa Scale adapted ${ }^{+}$for cross-sectional studies}

Selection: (Maximum 4 stars)

1) Representativeness of the sample ${ }^{*}$

a) Truly representative of the average in the target population*

b) Somewhat representative of the average in the target population*

c) No description of the derivation of the cohort

2) Sample size
a) Justified and satisfactory ${ }^{*}$
b) Not justified

3) Selection criteria

a) Selection criteria were clearly described and consecutive patients were included*

b) Selection criteria were not clearly described and it was unclear whether consecutive patients were included

4) Ascertainment of the exposurel|

a) Validated measurement tool*

b) Non-validated diagnostic measures (but the tool is available or described), or not all patients were DSA proven*

c) No description of the diagnostic tool

Outcome: (Maximum 3 stars)

1) Assessment of the outcome (description of cognitive tests applied)
a) Extensive neuropsychological evaluation**
b) $10^{*}$
c) Screening test*
d) No description

\section{2) Quantitative data:}

a) The study reported cognitive or intellectual functioning in children and adults that allowed analysis of quantitative data.*

b) The study did not report cognitive or intellectual functioning in children and adults that allowed analysis of quantitative data.

DSA, digital subtraction angiography; IQ, intelligence quotient.

The asterisk refers to the the number of stars $\left(^{*}\right.$ or ${ }^{* *}$ ) that can be assigned. It's a scoring method but not an actual footnote; 'This scale has been adapted by the authors from the Newcastle-Ottawa Quality Assessment Scale for cohort studies ${ }^{1}$ and the scale developed by Herzog et al. (2013) ${ }^{2}$ to perform a quality assessment of cross-sectional studies for the systematic review: 'Cognitive functions in children and adults with moyamoya vasculopathy: a systematic review and meta-analysis.' Since there were no groups to compare (only patients with moyamoya (no control groups) were reviewed for this systematic review), we

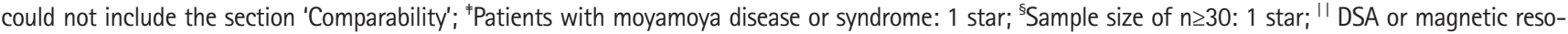
nance angiography: 1 star; ${ }^{\top}$ Neuropsychological test battery applied: 2 stars, 10 or screeningtest: 1 star. 
Supplementary Table 1. Applied cognitive instruments/tests for each study

\begin{tabular}{|c|c|}
\hline Study & Applied instruments/tests* \\
\hline Hsu et al. $(2014)^{3+}$ & $\begin{array}{l}\text { WISC-III or WISC-IV; WAIS-III } \\
\text { POI: Perceptual Organization Index } \\
\text { WMI: Working Memory Index } \\
\text { PSI: Processing Speed Index } \\
\text { WL1: Immediate Recall of the Word List } \\
\text { WL2: Delayed Recall of the Word List } \\
\text { WL-recog: Recognition of the Word List } \\
\text { CFT: Category Fluency Test } \\
\text { JLO: Judgment of Line Orientation }\end{array}$ \\
\hline Williams et al. $(2012)^{4+}$ & $\begin{array}{l}\text { WISC-III or WISC-IV; WAIS-III; WPPSI-III } \\
\text { VCI: Verbal Comprehension Index } \\
\text { PRI: Perceptual Reasoning Index } \\
\text { WMI } \\
\text { PSI }\end{array}$ \\
\hline Lee et al. $(2011)^{5+}$ & $\begin{array}{l}\text { KEDI-WISC-R } \\
\text { BGT recall: Bender Gestalt Test }\end{array}$ \\
\hline Imaizumi et al. $(1999)^{6+}$ & $\begin{array}{l}\text { WPPSI; WISC-R; WAIS-R; Tanaka-Bonet Intelligence Test } \\
\text { Tumori-Inage Mental Development Test }\end{array}$ \\
\hline Ohtaki et al. (1998) $)^{7+}$ & WAIS-R; WISC-R \\
\hline Matsushima et al. $(1997)^{8+}$ & WISC \\
\hline Matsushima et al. (1991) $)^{9+}$ & WISC; development questionnaires of Tsumori et al. \\
\hline Sato et al. $(1990)^{10+}$ & $\begin{array}{l}\text { WISC-R; WIPPSI; Developmental test } \\
\text { BGT }\end{array}$ \\
\hline Tagawa et al. (1989) ${ }^{11+}$ & WISC \\
\hline Ibayashi et al. $(1985)^{12+}$ & WAIS; Benton's Visual Memory Test \\
\hline Ishii et al. (1984) $)^{13+}$ & WISC; WAIS \\
\hline Lei et al. $(2017)^{14 \ddagger}$ & $\begin{array}{l}\text { TMT-B (s): Time consumed in the Trail Making Test part B } \\
\text { MES-EX: executive subtests of Memory and Executive Screening }\end{array}$ \\
\hline Kazumata et al. (2015) $)^{15 \neq}$ & $\begin{array}{l}\text { WAIS-III } \\
\text { WSCT: Wisconsin Sorting Test } \\
\text { TMT-A/B: Trail Making Test part A and B } \\
\text { CPT: Continuous Performance Test } \\
\text { Stroop test } \\
\text { RST: Reading Span Test }\end{array}$ \\
\hline Su et al. $(2013)^{16 t}$ & MoCA: Montreal Cognitive Assessment \\
\hline Calviere et al. (2012) ${ }^{17 \neq}$ & $\begin{array}{l}\text { Letter } R \\
\text { Category (animals) fluency test } \\
\text { TMT-A/B } \\
\text { Stroop interference condition } \\
\text { Brixton test } \\
\text { WCST-C/-P: Wisconsin Card Sorting Test number of categories and number of perseverations } \\
\text { Colored dots and word sections of the Stroop test } \\
\text { Verbal fluency tests } \\
\text { Naming and Recognition Test of } 80 \text { common objects } \\
\text { Rey figure copy test } \\
\text { Hooper test } \\
\text { Immediate and delayed } 16 \text { free and cued recalls } \\
\text { Rey figure recall }\end{array}$ \\
\hline
\end{tabular}


Supplementary Table 1. Continued

\begin{tabular}{ll}
\hline Study & \\
\hline Festa et al. (2010) & WAIS-III; WASI \\
& Hopkins Verbal Learning Test \\
& California Verbal Learning Test \\
& TMT-A/B \\
& Boston Naming Test \\
& Animal Fluency \\
& COWAT: Controlled Oral Word Association Test \\
& WCST: Wisconsin Card Sorting Test \\
& Grooved Pegboard Test \\
& Hand Dynometer \\
& WAIS-R; WAIS-III \\
& California Verbal Learning Test-II \\
& Memory Test-Revised Visual Reproduction subtest \\
& Delis-Kaplan Executive Function System Design Fluency Test \\
& FAS/AN: Letter and Category Fluency Tests \\
Karzmark et al. (2008) ${ }^{19+}$ & TMT-A/B \\
& Grooved Pegboard \\
& Tactile Form Recognition Test \\
& Boston Naming Test \\
\hline
\end{tabular}

This table represents the cognitive instruments/tests used in each study separately.

WISC (-R or -III or -IV), Wechsler Intelligence Scale (revised or third or fourth edition); WAIS (-R or -III), Wechsler Adult Intelligence Scale (revised or third edition); WPPSI (-III), Wechsler Preschool and Primary Scale of Intelligence (third edition); KEDI-WISC-R, Korean Educational Development Institute Wechsler Intelligence Scale for Children-Revised; WASI, Wechsler Abbreviated Intelligence Scale.

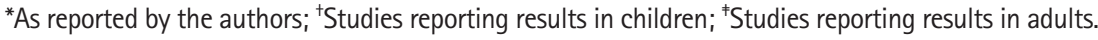


Supplementary Table 2. Predefined cognitive domains according to standard neuropsychological practice specified in Lezak ${ }^{20}$

\begin{tabular}{|c|c|}
\hline Cognitive domain & Included test \\
\hline \multicolumn{2}{|l|}{ General intelligence } \\
\hline \multirow{7}{*}{$\begin{array}{l}\text { Crystallised intelli- } \\
\text { gence }\end{array}$} & Verbal I0 \\
\hline & Similarities (WAIS) \\
\hline & Vocabulary (WAIS) \\
\hline & Information (WAIS) \\
\hline & Comprehension (WAIS) \\
\hline & National Adult Reading Test \\
\hline & Synonyms \\
\hline \multirow[t]{6}{*}{ Fluid intelligence } & Performal IQ \\
\hline & Raven Progressive Matrices \\
\hline & Picture Completion (WAIS) \\
\hline & Picture Arrangement (WAIS) \\
\hline & Arithmetic \\
\hline & Category Test \\
\hline \multicolumn{2}{|l|}{ Memory } \\
\hline \multirow[t]{4}{*}{ Working memory } & Digit Span Forward \& Backward \\
\hline & Block Span Forward \& Backward \\
\hline & Memory Scanning Test \\
\hline & Brown-Peterson task \\
\hline \multirow{22}{*}{$\begin{array}{l}\text { Learning \& Immedi- } \\
\text { ate memory }\end{array}$} & Logical Memory Immediate Recall \\
\hline & Visual Reproductions Immediate Recall \\
\hline & $\begin{array}{l}\text { Paired Associate Learning Immediate Recall } \\
\text { (verbal \& nonverbal) }\end{array}$ \\
\hline & Serial Digit Learning \\
\hline & Word List Immediate Recall \\
\hline & $\begin{array}{l}\text { (Buschke) Selective Reminding Test Immediate } \\
\text { Recall }\end{array}$ \\
\hline & Visual Retention Test Immediate Recall \\
\hline & Object Memory Immediate Recall \\
\hline & Rey Complex Figure Immediate Recall \\
\hline & Auditory Verbal Learning Test Immediate Recall \\
\hline & Serial Learning Test \\
\hline & Word/Picture Recognition Immediate Recall \\
\hline & Spatial Memory Test \\
\hline & California Verbal Learning Test Immediate Recall \\
\hline & Claeson-Dahl Test Immediate Recall \\
\hline & Seashore Tonal Memory Test \\
\hline & Figural Memory Immediate Recall \\
\hline & Iconic Memory \\
\hline & Maze Learning Immediate Recall \\
\hline & Tactual Performance Test Immediate \\
\hline & Prose Recall Immediate Recall \\
\hline & Symbol-Digit Learning Test \\
\hline
\end{tabular}

Supplementary Table 2. Continued

\begin{tabular}{|c|c|}
\hline Cognitive domain & Included test \\
\hline \multirow{2}{*}{$\begin{array}{l}\text { Learning \& Immedi- } \\
\text { ate memory }\end{array}$} & Babcock paragraph Immediate Recall \\
\hline & East Boston Memory Test Immediate Recall \\
\hline \multirow[t]{6}{*}{ Delayed memory } & Logical Memory Delayed Recall \\
\hline & Visual Reproductions Delayed Recall \\
\hline & Word List Delayed Recall \\
\hline & (Buschke) Selective Reminding Test Delayed Recall \\
\hline & Visual Retention Test Delayed Recall \\
\hline & Object Memory Delayed Recall \\
\hline \multirow[t]{34}{*}{ Cognitive domain } & Included test \\
\hline & Rey Complex Figure Delayed Recall \\
\hline & Auditory Verbal Learning Test Delayed Recall \\
\hline & $\begin{array}{l}\text { Paired Associate Learning Delayed Recall } \\
\text { (verbal \& nonverbal) }\end{array}$ \\
\hline & Word/Picture recognition delayed \\
\hline & California Verbal Learning Test Delayed Recall \\
\hline & Claeson-Dahl Test Delayed Recall \\
\hline & Figural memory Delayed \\
\hline & Maze Learning Delayed \\
\hline & Tactual Performance Test Delayed Recall \\
\hline & Delayed serial visual/verbal form memory task \\
\hline & Prose Recall Delayed \\
\hline & Babcock paragraph Delayed \\
\hline & East Boston Memory Test Delayed Recall \\
\hline & Logical Memory Delayed Recall \\
\hline & Visual Reproductions Delayed Recall \\
\hline & Word List Delayed Recall \\
\hline & (Buschke) Selective Reminding Test Delayed Recall \\
\hline & Visual Retention Test Delayed Recall \\
\hline & Object Memory Delayed Recall \\
\hline & Included test \\
\hline & Rey Complex Figure Delayed Recall \\
\hline & Auditory Verbal Learning Test Delayed Recall \\
\hline & $\begin{array}{l}\text { Paired Associate Learning Delayed Recall } \\
\text { (verbal \& nonverbal) }\end{array}$ \\
\hline & Word/Picture recognition delayed \\
\hline & California Verbal Learning Test Delayed Recall \\
\hline & Claeson-Dahl Test Delayed Recall \\
\hline & Figural memory Delayed \\
\hline & Maze Learning Delayed \\
\hline & Tactual Performance Test Delayed Recall \\
\hline & Delayed serial visual/verbal form memory task \\
\hline & Prose Recall Delayed \\
\hline & Babcock paragraph Delayed \\
\hline & East Boston Memory Test Delayed Recall \\
\hline
\end{tabular}


Supplementary Table 2. Continued

\begin{tabular}{|c|c|}
\hline Cognitive domain & Included test \\
\hline \multicolumn{2}{|l|}{ Processing speed } \\
\hline \multirow{7}{*}{$\begin{array}{l}\text { Psychomotor effi- } \\
\text { ciency }\end{array}$} & Digit Symbol Substitution \\
\hline & Symbol Digit Modalities Test \\
\hline & Trailmaking Test A \\
\hline & Grooved Pegboard \\
\hline & Purdue Pegboard \\
\hline & Graded Reaction Time Task \\
\hline & Perceptual Speed \\
\hline \multirow[t]{3}{*}{ Motor speed } & Simple reaction time \\
\hline & Fingertapping Test \\
\hline & Finger Oscillation Test \\
\hline \multicolumn{2}{|l|}{ Attention } \\
\hline \multirow[t]{3}{*}{ Visual attention } & Stroop Color Word Test Part I \& II \\
\hline & Facial Recognition Test \\
\hline & Target finding task \\
\hline \multirow[t]{2}{*}{ Sustained attention } & Digit Vigilance Test \\
\hline & Quatember \& Maly's Vigilance Test \\
\hline Divided attention & PASAT \\
\hline Selective attention & Stroop Color Word Test Part III \\
\hline Cognitive domain & Included test \\
\hline \multirow[t]{8}{*}{ Cognitive flexibility } & Lexical Fluency Task \\
\hline & Category Fluency Task \\
\hline & Trailmaking Test B (also C, D and Color) \\
\hline & Category Test \\
\hline & Concept Shifting Task \\
\hline & Wisconsin Card Sorting Task \\
\hline & Serial subtraction (3s of 7s) \\
\hline & Card Sorting \\
\hline \multirow{15}{*}{$\begin{array}{l}\text { Perception \& Con- } \\
\text { struction }\end{array}$} & Visual Retention Test Copy \\
\hline & Visual Reproductions Copy \\
\hline & Block Design \\
\hline & Clock Drawing \\
\hline & Rey Complex Figure Copy \\
\hline & Tactual Performance Test Part I \\
\hline & Object Assembly (WAIS) \\
\hline & Embedded Figures \\
\hline & De Renzi Rods \\
\hline & Flicker Fusion \\
\hline & Perception of spaced stimuli \\
\hline & Time judgement \\
\hline & Visual Recognition Threshold \\
\hline & Street Completion \\
\hline & Rosen figure drawing test \\
\hline
\end{tabular}

Supplementary Table 2. Continued

\begin{tabular}{ll}
\hline Cognitive domain & \multicolumn{1}{c}{ Included test } \\
\hline Language & (Boston) Naming Test \\
& Token Test \\
& Boston Diagnostic Aphasia Test Writing Scale \\
\hline
\end{tabular}

IQ, intelligence quotient; WAIS, Wechsler Adult Intelligence Scale. 


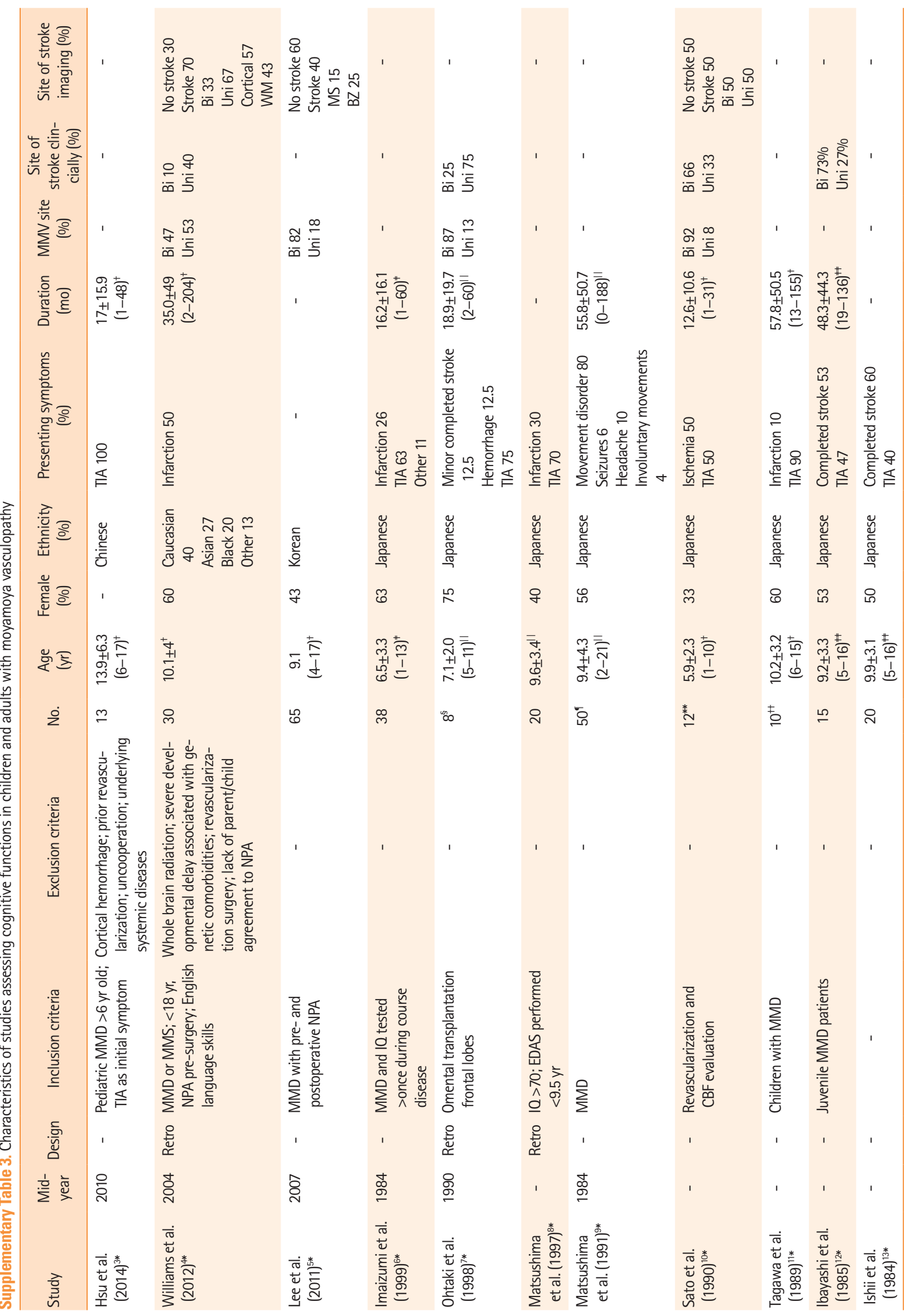




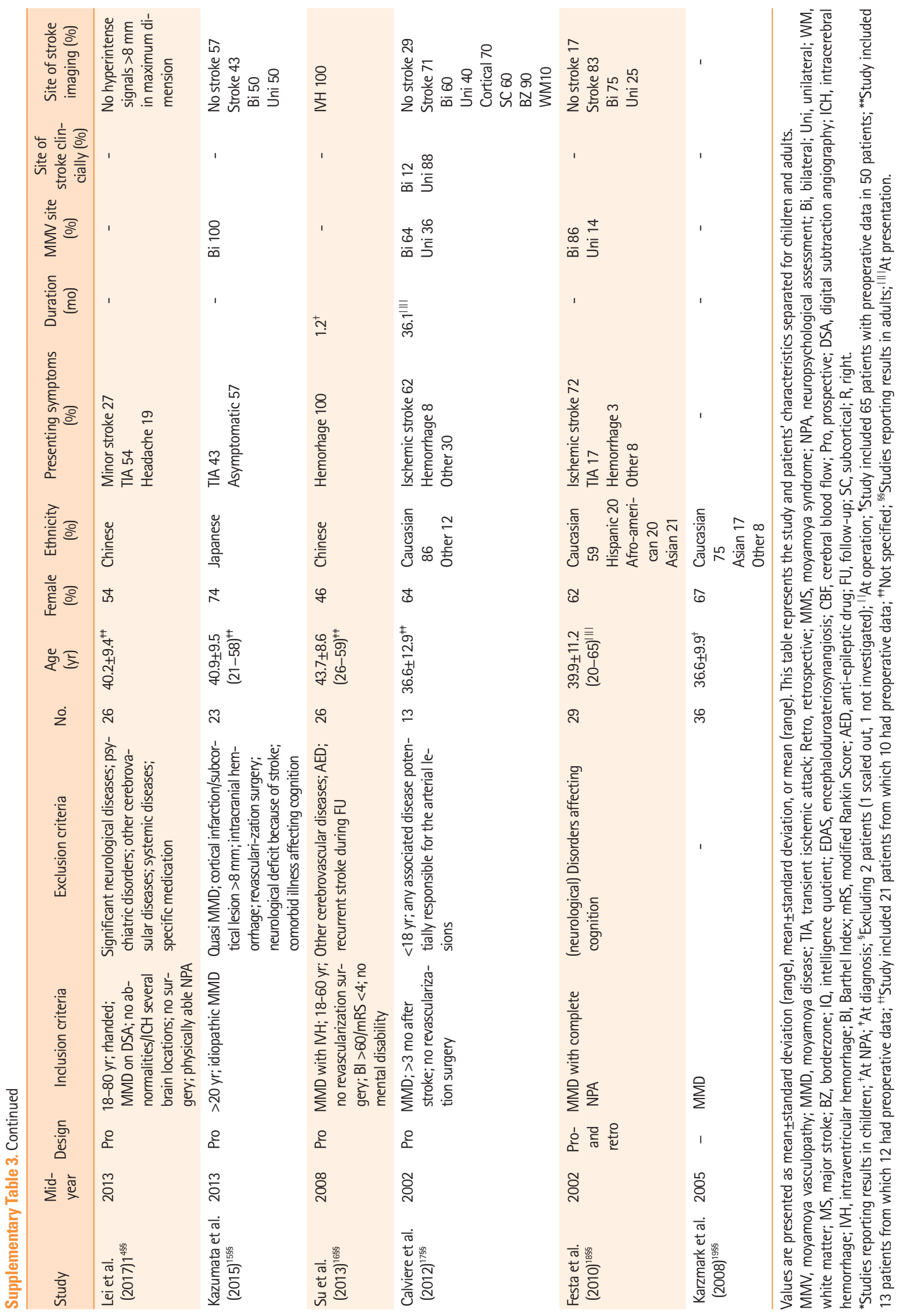




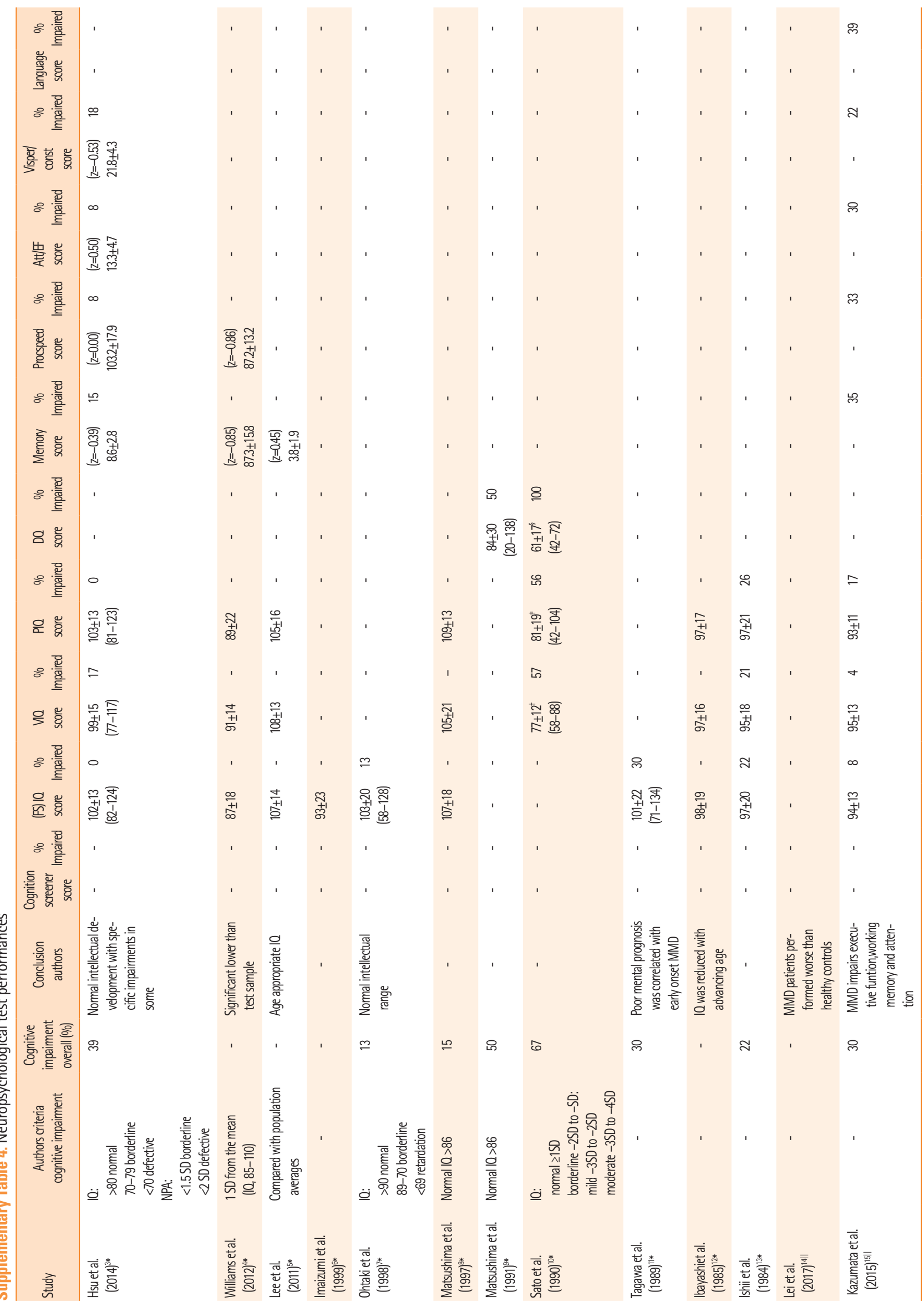




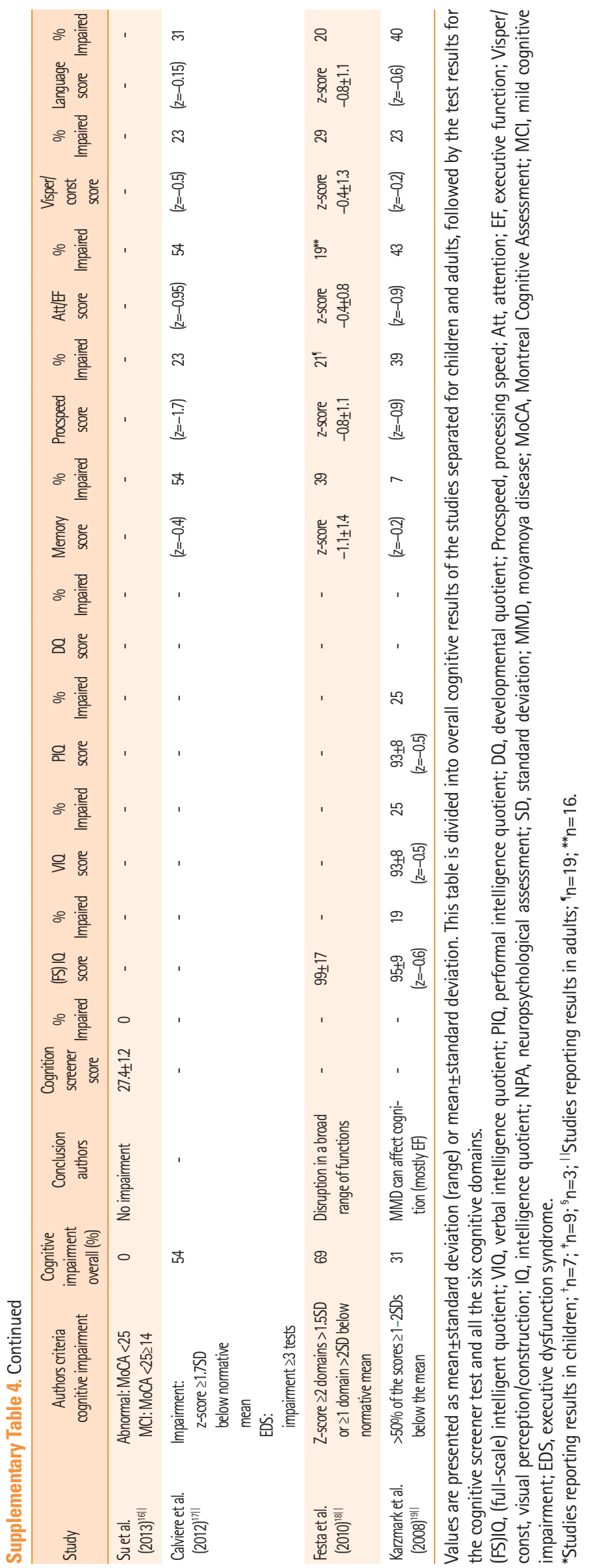




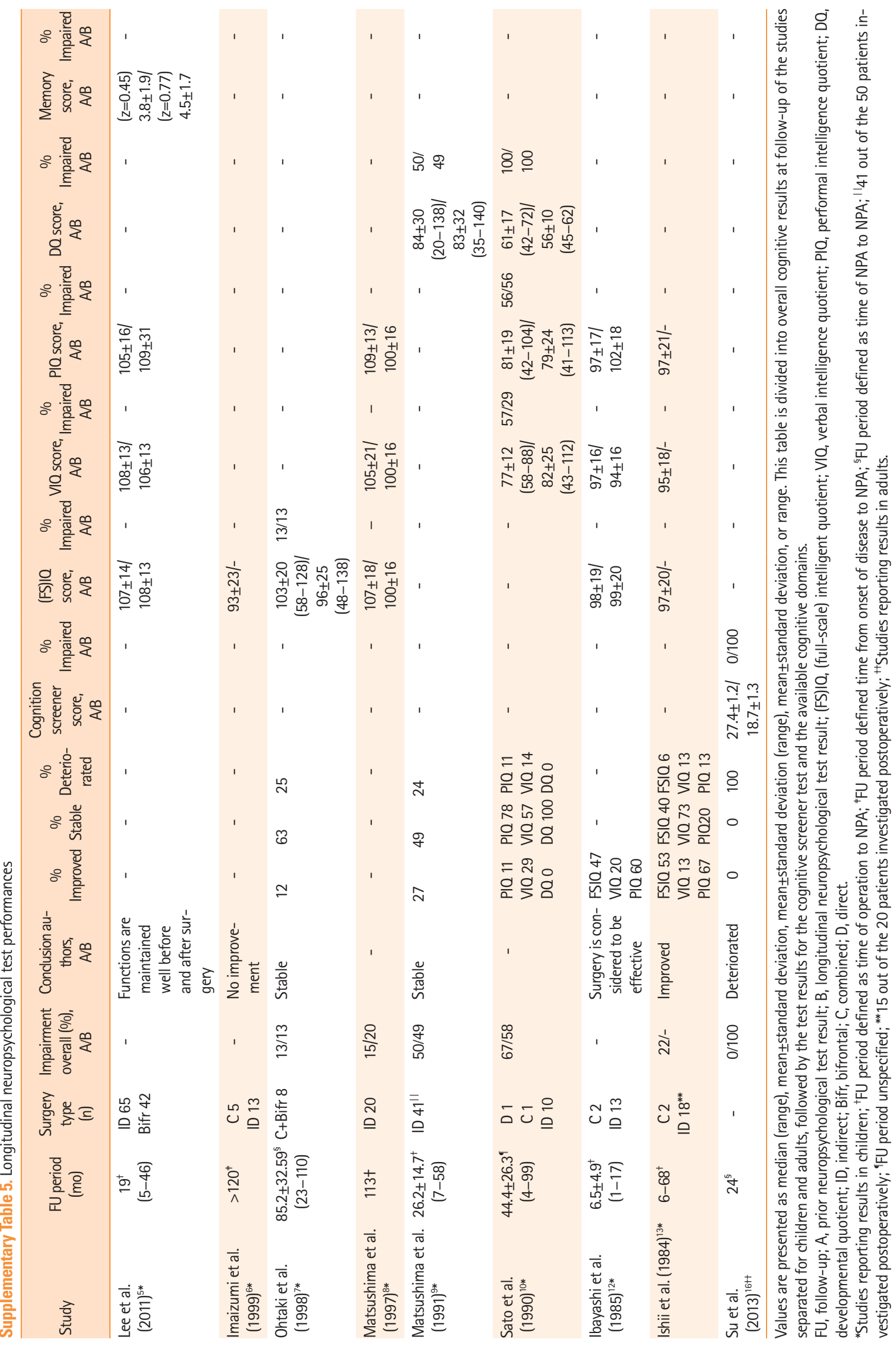


Supplementary Table 6. Critical appraisal of the included studies

\begin{tabular}{|c|c|c|c|c|c|c|c|}
\hline \multirow[b]{2}{*}{ Study } & \multirow[b]{2}{*}{ Study design } & \multicolumn{4}{|c|}{ Selection } & \multicolumn{2}{|c|}{ Outcome } \\
\hline & & $\begin{array}{c}\text { Representativeness } \\
\text { of the sample }\end{array}$ & $\begin{array}{l}\text { Sample } \\
\text { size }\end{array}$ & $\begin{array}{l}\text { Selection } \\
\text { criteria }\end{array}$ & $\begin{array}{l}\text { Ascertainment } \\
\text { of exposure }\end{array}$ & $\begin{array}{l}\text { Assessment } \\
\text { outcome }\end{array}$ & $\begin{array}{c}\text { Quantitative } \\
\text { data }\end{array}$ \\
\hline Hsu et al. $(2014)^{3 *}$ & Cross-sectional & + & & + & + & ++ & + \\
\hline Williams et al. $(2012)^{4 *}$ & Cross-sectional & + & + & + & + & ++ & + \\
\hline Lee et al. $(2011)^{5 *}$ & Cross-sectional & + & + & + & + & ++ & + \\
\hline Imaizumi et al. (1999)6* & Cross-sectional & + & + & + & & + & + \\
\hline Ohtaki et al. (1998) ${ }^{7 *}$ & Cross-sectional & + & & + & + & + & + \\
\hline Matsushima et al. (1997) ${ }^{8 *}$ & Cross-sectional & + & & + & + & + & + \\
\hline Matsushima et al. (1991) & Cross-sectional & + & + & + & & + & + \\
\hline Sato et al. (1990) ${ }^{10 *}$ & Cross-sectional & + & & + & + & + & + \\
\hline Tagawa et al. (1989) ${ }^{11 *}$ & Cross-sectional & + & & $?^{+}$ & $?^{+}$ & + & + \\
\hline lbayashi et al. (1985) & Cross-sectional & + & & $?^{+}$ & $?^{+}$ & + & + \\
\hline Ishii et al. (1984) & Cross-sectional & + & & & & + & + \\
\hline Lei et al. (2017) ${ }^{14 \ddagger}$ & Cross-sectional & + & + & + & + & + & + \\
\hline Kazumata et al. (2015) ${ }^{15 \neq}$ & Cross-sectional & + & & + & + & ++ & + \\
\hline Su et al. (2013) ${ }^{16 \neq}$ & Cross-sectional & + & & + & + & + & + \\
\hline Calviere et al. (2012) ${ }^{17 \neq}$ & Cross-sectional & + & & + & + & ++ & + \\
\hline Festa et al. (2010) ${ }^{18 \neq}$ & Cross-sectional & + & & + & + & ++ & + \\
\hline Karzmark et al. (2008) ${ }^{19 \neq}$ & Cross-sectional & + & + & & + & ++ & + \\
\hline
\end{tabular}

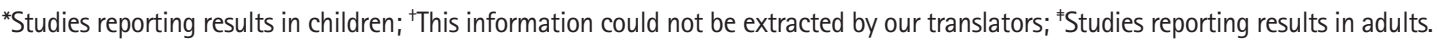




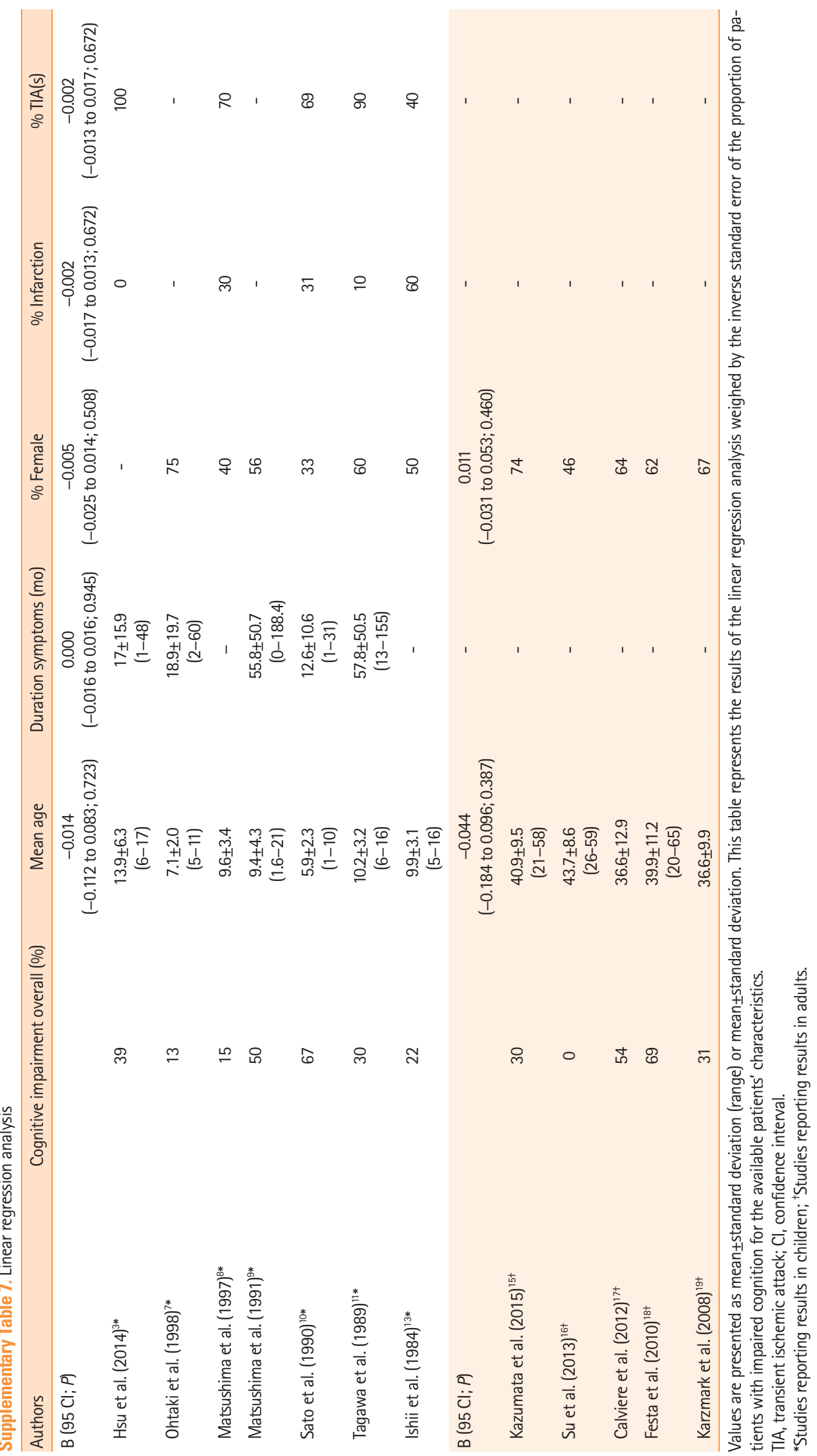




\section{Supplementary references}

1. Wells GA, Shea B, O'Connell D, Peterson J, Welch V, Losos M, et al. The Newcastle-Ottawa Scale (NOS) for assessing the quality of nonrandomised studies in meta-analyses. Ottawa Hospital Research Institute. http://www.ohri.ca/programs/clinical_epidemiology/oxford.asp. Accessed September 3, 2018.

2. Herzog R, Álvarez-Pasquin MJ, Díaz C, Del Barrio JL, Estrada $J M$, Gil Á. Are healthcare workers' intentions to vaccinate related to their knowledge, beliefs and attitudes? A systematic review. BMC Public Health 2013;13:154.

3. Hsu YH, Kuo MF, Hua MS, Yang CC. Selective neuropsychological impairments and related clinical factors in children with moyamoya disease of the transient ischemic attack type. Childs Nerv Syst 2014;30:441-447.

4. Williams TS, Westmacott $R$, Dlamini N, Granite L, Dirks P, Askalan $\mathrm{R}$, et al. Intellectual ability and executive function in pediatric moyamoya vasculopathy. Dev Med Child Neurol 2012;54:30-37.

5. Lee JY, Phi JH, Wang KC, Cho BK, Shin MS, Kim SK. Neurocognitive profiles of children with moyamoya disease before and after surgical intervention. Cerebrovasc Dis 2011;31:230237.

6. Imaizumi C, Imaizumi T, Osawa M, Fukuyama Y, Takeshita M. Serial intelligence test scores in pediatric moyamoya disease. Neuropediatrics 1999;30:294-299.

7. Ohtaki M, Uede T, Morimoto S, Nonaka T, Tanabe S, Hashi K. Intellectual functions and regional cerebral haemodynamics after extensive omental transplantation spread over both frontal lobes in childhood moyamoya disease. Acta Neurochir (Wien) 1998;140:1043-1053.

8. Matsushima $Y$, Aoyagi M, Nariai T, Takada Y, Hirakawa K. Long-term intelligence outcome of post-encephalo-duro-arterio-synangiosis childhood moyamoya patients. Clin Neurol Neurosurg 1997;99 Suppl 2:S147-S150.

9. Matsushima Y, Aoyagi M, Koumo Y, Takasato Y, Yamaguchi T,

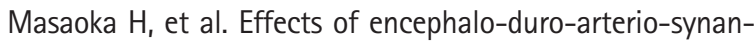
giosis on childhood moyamoya patients: swift disappearance of ischemic attacks and maintenance of mental capacity. Neurol Med Chir (Tokyo) 1991;31:708-714.
10. Sato H, Sato N, Tamaki N, Matsumoto S. Chronic low-perfusion state in children with moyamoya disease following revascularization. Childs Nerv Syst 1990;6:166-171.

11. Tagawa T, Itagaki Y, Mimaki T, Tanaka J, Ito N, Suzuki Y, et al. Intelligence and regional cerebral blood flow in children with Moyamoya disease. No To Hattatsu 1989;21:9-13.

12. Ibayashi K, Takeuchi S, Ishii R, Tanaka R, Tsuruoka H. Intelligence and memory function of juvenile patients with moyamoya disease. With reference to the effect of surgical treatment. Nerv Syst Child 1985;10:155-161.

13. Ishii $R$, Takeuchi $S$, Ibayashi $K$, Tanaka R. Intelligence in children with moyamoya disease: evaluation after surgical treatments with special reference to changes in cerebral blood flow. Stroke 1984;15:873-877.

14. Lei $Y$, Su J, Jiang $H$, Guo $Q$, Ni W, Yang $H$, et al. Aberrant regional homogeneity of resting-state executive control, default mode, and salience networks in adult patients with moyamoya disease. Brain Imaging Behav 2017;11:176-184.

15. Kazumata K, Tha KK, Narita $H$, Kusumi I, Shichinohe $H$, Ito M, et al. Chronic ischemia alters brain microstructural integrity and cognitive performance in adult moyamoya disease. Stroke 2015;46:354-360.

16. Su SH, Hai J, Zhang L, Yu F, Wu YF. Assessment of cognitive function in adult patients with hemorrhagic moyamoya disease who received no surgical revascularization. Eur J Neurol 2013;20:1081-1087.

17. Calviere L, Ssi Yan Kai G, Catalaa I, Marlats F, Bonneville F, Larrue $\mathrm{V}$. Executive dysfunction in adults with moyamoya disease is associated with increased diffusion in frontal white matter. $J$ Neurol Neurosurg Psychiatry 2012;83:591-593.

18. Festa JR, Schwarz LR, Pliskin N, Cullum CM, Lacritz L, Charbel $F$, et al. Neurocognitive dysfunction in adult moyamoya disease. J Neurol 2010;257:806-815.

19. Karzmark P, Zeifert PD, Tan S, Dorfman $\sqcup$, Bell-Stephens TE, Steinberg GK. Effect of moyamoya disease on neuropsychological functioning in adults. Neurosurgery 2008;62:10481051.

20. Lezak M, Howieson D, Bigler E, Tranel D. Neuropsychological Assessment. 5th ed. New York, NY: Oxford University Press, 2012. 